Clemson University

TigerPrints

Publications

Eugene T. Moore School of Education

3-2001

Multimedia and Engaged Reading in a Digital World

David Reinking

Follow this and additional works at: https://tigerprints.clemson.edu/eugene_pubs

Part of the Education Commons 


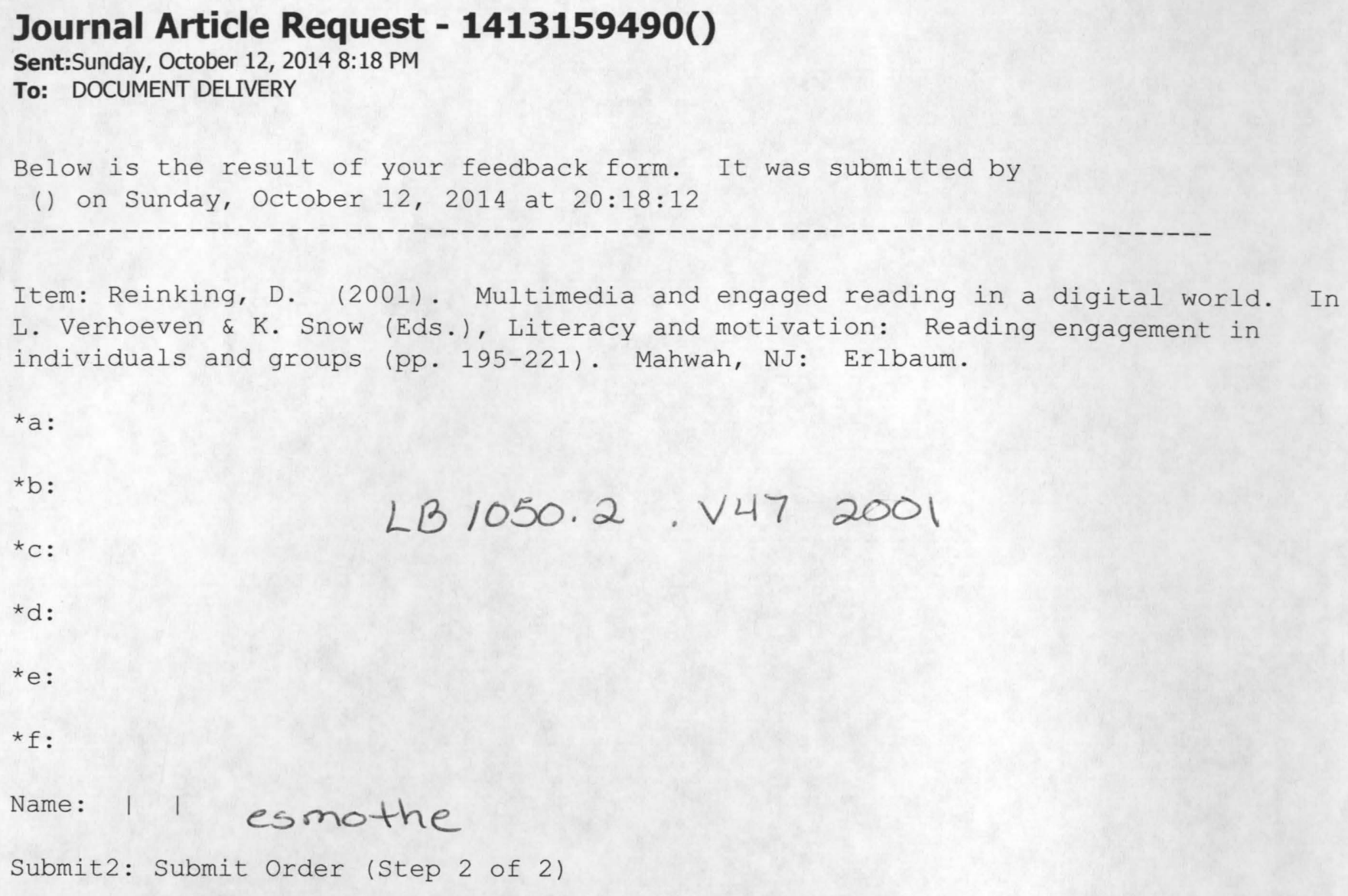


2w York: Dell.

zracies: Designing social futures. Harvard Edu-

ng as a cooperative diagnostic activity. Field $n$ of Field Service Managers International, pp.

s. London: Routledge and Kegan Paul.

Zornell University Press.

ess of literary understanding: Analysis of a classr: National Research Center on Literature

ideas of communties of learners. Mind, Culture

m. Cambridge, MA: Harvard University Press.

d the teaching of English. New Haven, CT: Yale

im formalism to post-structuralism. Baltimore,

gy: Vol. I(R. W. Rieber \& A. S. Carton, Eds.; N.

cting knowledge together. Portsmouth, NH:
10

\section{Multimedia and Engaged Reading in a Digital World}

\author{
David Reinking \\ University of Georgia
}

Anyone who has spent more than a few minutes "surfing the 'net" has an intuitive awareness of how different it feels to encounter textual information in a digital as opposed to a typographic environment. The inert features of the printed page that make reading essentially a solitary psycholinguistic process and only incidentally a visual one, as Goodman argued many years ago, are transformed on the computer screen to make reading more dynamic, more interactive, more essentially visual, and even auditory. In comparison, the experience of reading printed materials, especially books, as Richard Lanham (1993) has argued, is static, silent, introspective, and typically serious (see also Olson, 1994; Ong, 1982). These characteristics of conventional reading derived from printed materials have come to be culturally valued (see Birkerts, 1994, for a romantic expression of these values), and they have been reinforced, if not determined, by the material concreteness of conventional printed materials and the relative expense and difficulty in producing them.

Web pages and other electronic texts, on the other hand, regardless of their topic, purpose, or audience, seem mundane if they only simulate the staid features of printed texts. They more naturally invite authors and readers to exploit a variety of visual and auditory effects that on the computer screen compete equally with the alphabetic code for space and attention (Bolter, 1991; Lanham, 1993). The experience of reading in digital environments, therefore, is typically more sensuous, interactive, and playful, in part because electronic texts make available an array of audiovisual effects 
that can be integrated flexibly in interesting and creative ways. Animated graphics, sound effects, synthesized and digital speech, and full-motion video can be combined with the written prose and static graphics to which the technology of print has traditionally been limited.

This capability to juxtapose flexibly so many audiovisual representations in a single, seamless display is why the term multimedia has been associated with electronic texts. Thus, one dimension of contemplating how electronic texts may shape or promote literacy in comparison to conventional texts is to analyze them as multimedia documents. Specifically, given the focus of this book, it might be asked whether the fact that electronic texts can be multimedia documents has any bearing on promoting engagement in reading. The rapidly expanding presence of digital texts in increasingly diverse areas of daily life including schooling makes this a timely and potentially consequential issue.

In this chapter I examine electronic texts specifically as multimedia artifacts and how as such they might relate to engaged reading. I do so in the context of a larger discussion among some literacy researchers who are struggling to define what a text is and what literacy is in an increasingly post-typographic world (Cognition and Technology Group at Vanderbilt University, 1991; Flood \& Lapp, 1995; Reinking, 1995; Reinking, McKenna, Labbo, \& Kieffer, 1998). That ongoing discussion includes the development of theoretical perspectives that capture the uniqueness of digital texts across several dimensions, ultimately aimed at improving their quality, their effectiveness in promoting learning, and their contribution to enhancing literacy education.

To address electronic texts as multimedia artifacts I begin by considering historically what is meant by the term multimedia as it has been used in the conventional discourse of education and more currently as a theoretical construct. Then I propose several assertions derived from current theoretical views of how printed and electronic texts differ. These assertions argue that electronic texts as multimedia documents may be inherently more engaging to more readers than are conventional printed texts. In a subsequent section I illustrate these assertions and the potential of exploiting the multimedia capabilities of electronic text by describing a research project in which my colleagues and I involved teachers and students in creating multimedia book reviews as an alternative to the conventional book report.

\section{MULTIMEDIA OR MEDIUM?}

The term multimedia means literally "many media," but that definition begs an important question: What exactly is a medium or, more precisely, how can one medium be distinguished from another? As in most areas of in- 
'esting and creative ways. Animated and digital speech, and full-motion n prose and static graphics to which ly been limited.

ly so many audiovisual representahy the term multimedia has been asne dimension of contemplating how e literacy in comparison to convennedia documents. Specifically, given :ed whether the fact that electronic $s$ any bearing on promoting engage? presence of digital texts in increasig schooling makes this a timely and

texts specifically as multimedia artie to engaged reading. I do so in the some literacy researchers who are I what literacy is in an increasingly d Technology Group at Vanderbilt Reinking, 1995; Reinking, McKenna, iscussion includes the development ire the uniqueness of digital texts aimed at improving their quality, $g$, and their contribution to enhanc-

media artifacts I begin by considerm multimedia as it has been used in $\mathrm{n}$ and more currently as a theoretisertions derived from current theonic texts differ. These assertions ardocuments may be inherently more ventional printed texts. In a subse$s$ and the potential of exploiting the xt by describing a research project teachers and students in creating ve to the conventional book report.

ny media," but that definition begs a medium or, more precisely, how another? As in most areas of in- quiry, to move from intuitive to theoretical answers, precise definitions are needed. For example, considering digital texts as "multimedia" artifacts at all may be misleading or at least theoretically shallow. Conceptualizing digital texts as multimedia artifacts might for the sake of analysis be more productively viewed as a configuration of symbol systems defining a single medium. So one issue that must be addressed theoretically is whether digital texts might be considered multimedia or a single medium with diffuse symbol systems. That distinction has theoretical implications and perhaps practical ones as well. In this section, therefore, I discuss the antecedents of considering multimedia and engaged reading, first by considering multimedia historically in relation to research and then in relation to a more recent and elaborated theory of instructional media and reading digital texts.

\section{A Historical Perspective}

In everyday speech, media usually refers to a means of mass communication, for example, the news media, or to forms of artistic expression such as watercolors or marble. To educators, media have been viewed more as individual technologies that might be used for instruction. In considering educational media, educators and educational researchers have been interested in global and often atheoretical issues such as how much students learn when they are alternatively presented content in various media such as a film, a slide presentation, an audio recording, or a book. Books are clearly a technology, but their unexamined centrality in education, and indeed in Western culture, is reflected by that fact that they are rarely seen as such (Reinking, 1997). In fact, educational media and the technologies that define them are often judged solely on how they compare with a book in producing comprehension and learning. Consequently, among literacy educators in particular, questions about media are often naively seen as an issue of books versus technology.

Indeed, the early research investigating electronic texts was guided first by the assumption that electronic texts represented little more than a change in the technology of how texts were presented. Such studies, which I have categorized as convergent studies (Reinking, 1992; Reinking \& Bridwell-Bowles, 1991), compared reading with and without a computer under conditions that typically varied only to the extent that otherwise identical texts were displayed on a computer screen or on printed pages. Findings typically provided little, if any, support for reading on a computer screen over printed pages. For example, on the computer screen reading speed was slower (Gould \& Grischkowsky, 1983; Hansen, Doring, \& Whitlock, 1978; Kruk \& Muter, 1984; Muter, Latremouille, Treurniet, \& Beam, 1982), performance on multiple-choice tests presented on the computer was poorer (Heppner, Anderson, Farstrup, \& Weiderman, 1985), and com- 
prehension was no different when comparing the alternative displays (Fish \& Feldman, 1987; Gambrell, Bradley, \& McLaughlin, 1987). These "horserace" comparisons, which were often atheoretical (i.e., there was no basis for predicting or interpreting differences), have been criticized frequently in the literature (Reinking \& Bridwell-Bowles, 1991).

Gradually, however, researchers came to realize that such superficial uses of the technology to vary only the visual display of text were less important than how electronic texts might differ conceptually from printed texts; researchers began to conduct what I have characterized as divergent studies (Reinking, 1992; Reinking \& Bridwell-Bowles, 1991). That is, they began to investigate how the technological capabilities afforded by electronic texts might diverge from printed texts beyond simply differences in their visual display. Some examples include providing various types of assistance during reading (e.g., Blohm, 1982, 1987; Reinking, 1988; Reinking \& Rickman, 1990; Reinking \& Schreiner, 1985), providing adaptive guidance and feedback (e.g., MacGregor, 1988a, 1988b), exploring the effects of nonlinear reading of hypertexts (e.g., Spiro, Feltovitch, Jacobson, \& Coulson, 1992), presenting textual information electronically under conditions aimed at affecting readers' strategies (e.g., Reinking, Pickle, \& Tao, 1996; Salomon, Globerson, \& Guterman, 1989; Tobias, 1987, 1988), providing students with immediate access to multiple documents describing conflicting perspectives (Stahl, Hynd, Britton, McNish, \& Bosquet, 1996), and, most relevant to the current topic, using auditory and visual effects made possible by the computer (e.g., Hegarty, Carpenter, \& Just, 1991; Reitsma, 1988; Sherwood, Kinzer, Hasselbring, \& Bransford, 1987). More often than not, divergent studies have produced results suggesting that, at least under certain conditions, digital texts do have some advantages over printed texts in increasing comprehension and learning and in influencing reading strategies.

More recently, I would argue, educators and researchers are moving to an even more liberal and less biased view of digital texts that goes beyond thinking of them simply as unproven alternatives to conventional print. Put another way, digital texts are moving closer to the mainstream of reading and writing. For example, early studies compared students writing with pencil and paper and with word processors (e.g., Collier, 1983; Daiute, 1986). Such studies are no longer considered relevant because no study, regardless of the strength of its findings, would convince anyone that word processing should be abandoned. Likewise, few would consider abandoning the World Wide Web as a source of textual information, regardless of how many studies might show it to be in some way inferior to printed materials. Researchers today are, correctly I think, much more interested in investigating how digital texts might be presented and used more effectively than in comparing them to printed materials-what Wright (1987) calls intrarather than intermedia comparisons. 
nparing the alternative displays (Fish \& McLaughlin, 1987). These "horseatheoretical (i.e., there was no basis ces), have been criticized frequently
Bowles, 1991).

ame to realize that such superficial le visual display of text were less imght differ conceptually from printed hat I have characterized as divergent dwell-Bowles, 1991). That is, they beal capabilities afforded by electronic beyond simply differences in their viroviding various types of assistance Reinking, 1988; Reinking \& Rickman, 'viding adaptive guidance and feedploring the effects of nonlinear read:h, Jacobson, \& Coulson, 1992), preically under conditions aimed at king, Pickle, \& Tao, 1996; Salomon, $1987,1988)$, providing students with nts describing conflicting perspecosquet, 1996), and, most relevant to risual effects made possible by the ust, 1991; Reitsma, 1988; Sherwood, '). More often than not, divergent ig that, at least under certain conditages over printed texts in increasinfluencing reading strategies. ors and researchers are moving to w of digital texts that goes beyond ernatives to conventional print. Put oser to the mainstream of reading compared students writing with ors (e.g., Collier, 1983; Daiute, 1986). elevant because no study, regardconvince anyone that word procw would consider abandoning the l information, regardless of how way inferior to printed materials. much more interested in investied and used more effectively than -what Wright (1987) calls intra-
To summarize what I think are relevant points for making the assertions that follow in a subsequent section:

1. Media in education have been viewed primarily in terms of technologies.

2. Books and other conventional printed materials are technologies even though they have not been viewed as such.

3. Digital texts have been shown to have some advantages over printed texts when viewed in terms of their conceptual as opposed to more superficial visual differences.

4. It is short-sighted and unproductive to evaluate the potential of digital texts only in terms of how they compare to conventional printed texts.

\section{A Theoretical View of Media}

Although important to my assertions, these points still beg the question of what a medium is and how one medium can be distinguished from another. To address that issue, I have drawn in my own work on the theoretical perspective of Gavriel Salomon as presented most thoroughly in his seminal book entitled Interaction of Media, Cognition, and Learning (1979). He argued that popular intuitive conceptions of media will lead to no more than superficial understandings of media and their potential consequence for cognition and learning. He proposed instead that a medium should be defined and analyzed in relation to four attributes: contents, situations of use, technologies, and symbol systems. A particular medium, then, can be defined in terms of its unique configuration of attributes in these four areas. For example, the symbol systems of television and film (or, more aptly, cinema) are similar but their technologies, situations of use, and contents typically vary. It is a relatively stable configuration of attributes within these four categories that defines a medium, separating it from other media.

According to Salomon (1979), "media are our cultural apparatus for selecting, gathering, storing, and conveying knowledge in representational forms, [and] representation, as distinguished from raw experience, is always coded within a symbol system" (p. 3). Thus, to Salomon, of the four classes of media attributes, the symbol systems and the technologies that make them available are the most critical factors in affecting or effecting cognition and learning. The unique symbols systems afforded by particular technologies require specific cognitive skills to extract information from them and consequently determine what cognitive skills become well practiced. Furthermore, symbol systems and the technologies that make them possible vary in the degree to which they can supplant needed skills for those who lack them. 
Situations and contents, although important to separating media, are only correlated with a particular medium. For example, cinematography has typically been associated with viewing certain genres of drama (contents) in a theater where people go for entertainment (the situational context). One can go to a movie theater to view a documentary (e.g., movies shown in a museum), but such situations are atypical of the medium of film, whereas they are more typical of television and video.

\section{Applying Salomon's Theoretical Framework to Multimedia and Reading}

I believe Salomon's theoretical framework is useful in considering the topic of multimedia and reading. First, his framework allows digital texts to be considered theoretically a distinctly new medium of communication, not just a new technology for extending an old one. In other words, digital texts are not just printed texts that happen to be displayed on a computer screen. More directly relevant to the present discussion, neither is it appropriate, given Salomon's theoretical position, to conceptualize digital texts as simply a combination of existing media, as is perhaps implied by the term multimedia. Instead, digital texts might better be conceived as a unique configuration of symbol systems, technologies, contents, and situations of use.

Even a superficial analysis of digital texts along these four dimensions reveals some clearly identifiable differences between printed and digital texts, which is the first step in establishing that they can be considered separate media. As I pointed out in the beginning of this chapter, digital texts make available a wider range of symbol systems than do printed texts. Indeed, that is why they are often described with the term multimedia. Likewise, in considering the category of technology, the computer obviously provides a range of options and contingencies quite unlike print. Although the content of printed and digital texts is theoretically unlimited, the content of digital texts is often much more open-ended, less often divided into discrete units, and increasingly more accessible (e.g., the World Wide Web). Situations of use are currently different too (e.g., the common observation of bibliophiles who remind us that computers are not conducive to reading in bed or on the beach) but are likely to change as the technology becomes more portable and convenient to use.

According to Salomon, even more important in defending the argument that printed and digital texts are different media is finding evidence that they can uniquely affect and effect cognitive processes. The empirical evidence in that regard is fairly well established, perhaps not surprisingly so given the major differences between printed and digital texts in terms of symbol systems and technologies. For example, in his own work (Salomon 
h important to separating media, are edium. For example, cinematography viewing certain genres of drama (confor entertainment (the situational conto view a documentary (e.g., movies ons are atypical of the medium of film, evision and video.

\section{ramework}

work is useful in considering the topic framework allows digital texts to be new medium of communication, not $n$ old one. In other words, digital texts pen to be displayed on a computer present discussion, neither is it approosition, to conceptualize digital texts media, as is perhaps implied by the xts might better be conceived as a ms, technologies, contents, and situa-

I texts along these four dimensions rerences between printed and digital hing that they can be considered sepeginning of this chapter, digital texts ol systems than do printed texts. Inribed with the term multimedia. Liketechnology, the computer obviously ngencies quite unlike print. Although is is theoretically unlimited, the cone open-ended, less often divided into e accessible (e.g., the World Wide ifferent too (e.g., the common obserhat computers are not conducive to e likely to change as the technology nt to use.

mportant in defending the argument rent media is finding evidence that nnitive processes. The empirical eviblished, perhaps not surprisingly so orinted and digital texts in terms of example, in his own work (Salomon et al., 1989), Salomon showed how the computer can act as a "reading partner" to improve comprehension among low-ability readers. Likewise, Spiro, Coulson, Feltovich, and Anderson (1988) showed that hypertexts can effect positive changes in learning content in what they call ill-structured domains such as conducting medical diagnoses. Hegarty et al. (1991) were able to show how digital texts can through animation supplant the cognitive skills unavailable to participants with low mechanical ability in learning the operation of a machine. In our own work, my colleagues and I (Reinking, Pickle, \& Tao, 1996) have extended Tobias's $(1987,1988)$ work studying how mandatory review after incorrect responses to questions affects study strategies and learning of digital texts. These and similar studies indicate at least short-term cognitive effects, what Salomon called effects with media, and raises the possibility of long-term effects, what Salomon called effects of media (1979; see also Salomon, Perkins, \& Globerson, 1991).

The point I wish to make through this analysis is that it may be appropriate to associate the term multimedia with digital texts in considering topics such as engaged reading. However, it may be inappropriate or misleading to do so if by using the term, we mean only that digital texts are essentially printed texts supplemented by some other media such as film or music. On the other hand, the term may be appropriate and useful if we see it as emphasizing that digital texts are a unique medium, separate from printed texts mainly because, unlike printed texts, they entail a wide variety of symbol systems. The latter perspective opens up the possibility of considering the extent to which digital texts might be engaging in ways not available in printed forms. Although our biases toward print may seek to make that comparison a threatening competition, it need not be so any more than an analysis of the advantages and limitations and the consequent potential uses of any media.

\section{HOW MIGHT DIGITAL TEXTS PROMOTE ENGAGED READING?}

The concept of engaged reading has strong intuitive appeal, capturing many of the ultimate goals of educators interested in promoting literacy beyond rudimentary decoding ability. However, engaged reading is not an easy concept to define precisely. It may not be too much of an exaggeration to say that trying to define engaged reading precisely is akin to the frustrated response of a U.S. Supreme Court Justice when he was pressed for a definition of pornography. He said something to the effect of, "I don't know what it is, but I know it when I see it." Likewise, most teachers could easily identify students whom they would categorize as engaged readers and others who are not, even if they could not define the term precisely. And it is 
perhaps worth noting that the differences between students who might be described as engaged readers may be as noteworthy as their similarities. Suggesting that engaged reading may not be precisely defined may be somewhat unfair to researchers who have tried to define it more precisely, including myself (e.g., Alvermann \& Guthrie, 1993; Baker, Afflerbach, \& Reinking, 1996). However, these definitions often contain other rather broad, amorphous, and question-begging concepts such as strategic reading, critical reading, motivated reading, reading for enjoyment, and so forth.

Although it may be unsatisfactory from a theoretical perspective, it may not be critical to press for a precise definition of engaged reading. Rather, it may be more important to focus on achieving rather than defining a goal that has strong intuitive appeal. Likewise, it may sometimes be difficult to assert precisely what conditions may promote engaged reading, but in this area there is more pedagogical theory or tradition that can be drawn on for guidance, although some of that tradition too may be founded on more intuitive ideas than most of us would like to admit. All this is to say that in making the assertions that follow about conditions that may promote engaged reading and how digital texts may uniquely further those conditions, I do not devote much space to defending the claims that certain conditions promote engagement in reading. Instead, I focus on arguments concerning how digital texts are unique in helping to create the conditions that are agreed to promote reading engagement.

\section{Active Orientation to Texts}

Readers will be more engaged when they read under conditions that create an active rather than a passive orientation to texts. For more than 20 years, we have been aware that successful reading requires a reader who is cognitively active in processing information presented in a text. For example, when reading a text, readers must activate their existing knowledge, connect it to the content of the text, monitor their own understanding, and employ appropriate strategies if they are having difficulty. Indeed, such activity would undoubtedly be part of any definition of engaged reading. Theoretical orientations highlighting the importance of active reading describe reading as an interaction or transaction between a text and a reader. However, this interaction is figurative, not literal, because it is entirely. onesided. That is, because texts are static and inert, the entire burden of activity is on the side of the reader. If a reader cannot be or chooses not to be active or engaged, a printed text can do nothing to promote the active orientation that is necessary to successful reading.

Gradually, however, we are coming to understand that digital texts and the symbol systems they entail can create a reading experience that is literally interactive (see Leu \& Reinking, 1996). That is, unlike printed texts, digi- 
nces between students who might be e as noteworthy as their similarities. ay not be precisely defined may be have tried to define it more precisely, : Guthrie, 1993; Baker, Afflerbach, \& finitions often contain other rather ging concepts such as strategic readऽ, reading for enjoyment, and so forth. from a theoretical perspective, it may efinition of engaged reading. Rather, it achieving rather than defining a goal wise, it may sometimes be difficult to promote engaged reading, but in this or tradition that can be drawn on for ion too may be founded on more intuto admit. All this is to say that in makonditions that may promote engaged iquely further those conditions, I do he claims that certain conditions proI focus on arguments concerning how create the conditions that are agreed

hey read under conditions that create ation to texts. For more than 20 years, l reading requires a reader who is nation presented in a text. For examist activate their existing knowledge, nonitor their own understanding, and are having difficulty. Indeed, such acay definition of engaged reading. Themportance of active reading describe on between a text and a reader. Howot literal, because it is entirely oneand inert, the entire burden of activader cannot be or chooses not to be do nothing to promote the active oriul reading.

to understand that digital texts and eate a reading experience that is liter96). That is, unlike printed texts, digi- tal texts, through the computer programs that present them contingently to a reader, can respond in a variety of different ways to promote active reading. Digital texts can present text in such a way as to guarantee that a reader must be active, and they can be modified automatically or at the request of a reader. A single digital text, which need not be the same for all readers, can take on some of the burden of helping the reader to become appropriately engaged.

There are many other ways of conceptualizing this assertion and a wide range of examples of how digital texts can require or encourage an active orientation to reading. For example, Landow (1992) pointed out that digital texts, particularly hypertexts, which do not have the single linear and hierarchical structure characteristic of printed texts, blur the distinction between a reader and a writer. Readers can be passive but writers cannot, as Roland Barthes (1970/1974) pointed out by making the distinction between what he calls "readerly" and "writerly" texts. Hypertexts in particular and digital texts in general instantiate this view implicitly and explicitly. For example, readers of hypertext implicitly become writers when they must choose their own paths through linked textual nodes. Readers can, on the other hand, explicitly assume the role of author because the margins of digital texts, figuratively speaking, are infinitely large. That is, unlike the literal margins of the printed page, which typically provide little room for reader input, digital texts are not limited by margins because they can easily be enlarged, revised, enhanced, and extended. This possibility is greatly facilitated by flexible cut-and-paste functions that are becoming standard across many different applications and textual displays. Some hypertexts even are explicitly designed to invite the reader to become an author. One such hypertext is Marble Springs (Larson, 1993), which used written poems, maps, and other simple graphical representations to portray characters and events in an imaginary pioneer town in the 1800 s. However, readers were provided with tools to extend the town's "story" by adding their own characters and poems, which might include a variety of audio and visual effects.

As this example suggests, the availability of various symbol systems for creating digital texts might enhance further the active orientation to reading that digital texts naturally promote. Readers of digital texts are often presented with the opportunity to select from among and to juxtapose a variety of symbolic representations in the process of reading. Not only must readers sometimes select from among various media that are available, but they must make a more explicit choice about when it would be most appropriate to do so.

Relatively little is known about how the more active orientation to reading that digital texts seem to create may affect the reading and learning of a particular text, let alone what the effects of reading such texts over an extended time might be. However, there are some findings that suggest direc- 
tions for further research. For example, Spiro et al. (1988) showed that hypertexts can effect positive changes in learning content in what they call ill-structured domains such as conducting medical diagnoses. Medical students reading hypertexts, when compared to those reading conventional printed texts, did less well in recalling factual information but were more able to apply the information in conducting a diagnosis, presumably because they had to more actively construct connections among the nodes of information and because their complex interrelationships could be shown through the hypertext. These and other studies (e.g., Reinking et al., 1996; Tobias, 1987, 1988) demonstrated that digital texts have the capability to engage readers more actively in processing textual information. Thus, there is some evidence that digital texts can enhance readers engagement with texts in learning expository content, at least in the short term.

\section{Easy Rather Than Difficult Reading}

Readers will be more engaged when reading is easy rather than difficult. Considering the relative difficulty of texts is firmly embedded in theoretical and pedagogical understandings of reading. For example, the rationale for the development of readability formulas is that establishing a relative estimate of textual difficulty is useful for instructional purposes. Indeed, a principle of reading pedagogy is that teachers should be conscious of how difficult texts are, particularly whether they are at a frustration, independent, or instructional level. That is, teachers should avoid situations in which texts are so difficult that students may become frustrated in trying to read them. Texts classified at the independent level are considered to be easy enough that students require no assistance to read them, whereas texts at an instructional level are considered appropriately challenging to extend students abilities with appropriate support from a teacher or other more competent reader. Put in terms of engagement, it is customarily considered unlikely that students will become motivated to read, that is, engaged in reading, texts that are too easy or too difficult. A similar rationale is the basis for Stanovich's (1986) explication of the Matthew effects to explain why poor readers fall further and further behind good readers. Taken from the biblical passage in the book of Matthew stating that the rich get richer and the poor get poorer, Matthew effects highlight the fact that poor readers must more often than good readers contend with difficult texts, which discourages poor readers from engaging in reading, which reduces their motivation to read, which in turn provides less opportunity to obtain the benefits of reading. Better readers, on the other hand, experience fewer frustrating texts, receive intrinsic or extrinsic rewards for their success, and are therefore likely to read more. Pedagogically and theoretically, 
sle, Spiro et al. (1988) showed that in learning content in what they call ting medical diagnoses. Medical sturared to those reading conventional y factual information but were more lucting a diagnosis, presumably beuct connections among the nodes of $\mathrm{x}$ interrelationships could be shown er studies (e.g., Reinking et al., 1996; ligital texts have the capability to enng textual information. Thus, there is enhance readers engagement with t least in the short term.

reading is easy rather than difficult. xts is firmly embedded in theoretical tding. For example, the rationale for as is that establishing a relative estiistructional purposes. Indeed, a priners should be conscious of how diffiey are at a frustration, independent, rs should avoid situations in which become frustrated in trying to read lent level are considered to be easy ance to read them, whereas texts at appropriately challenging to extend oport from a teacher or other more gement, it is customarily considered tivated to read, that is, engaged in difficult. A similar rationale is the bathe Matthew effects to explain why ehind good readers. Taken from the $v$ stating that the rich get richer and highlight the fact that poor readers ntend with difficult texts, which dis$n$ reading, which reduces their motiless opportunity to obtain the benehe other hand, experience fewer extrinsic rewards for their success, e. Pedagogically and theoretically, therefore, the more often readers encounter texts that are too difficult, the less likely, overall, they might be expected to be engaged readers and the more likely they are to acquire a general aversion to reading.

Thus, it is important to note that digital texts undermine current understandings of textual difficulty. That is, what makes printed texts difficult or easy is determined directly by their available symbol systems and technologies. Because digital texts entail a much different set of symbol systems and technologies, they are not necessarily bound by the same concepts of difficulty. For example, there is an extensive research literature devoted to investigating how difficulty can be moderated in printed texts while increasing engagement. Advance organizers, inserted questions, and concept maps are a few examples. Although some of these have proven marginally effective, these efforts pale in comparison to the range of assistance that might be included in digital texts to assist a particular reader independently reading a particular text.

For example, there have been many studies investigating the effects of providing various forms of assistance to readers while reading digital texts (e.g., Blohm, 1982, 1987; MacGregor, 1988a, 1988b; Reinking, 1988; Reinking \& Rickman, 1990; Reinking \& Schreiner, 1985). An early example of contingent displays using only the computer's capability to sample and analyze input is a study by L'Allier (1980), who used a computer to simplify, as needed, the structure, content, vocabulary, and so forth of written prose based on a complex algorithm that took into account factors such as reading rate and response times to inserted questions. Poor high school readers reading the adaptive digital texts performed as well on a postexperimental comprehension measure as good readers. It is not difficult to imagine other more technologically sophisticated input that might be used to monitor readers' difficulty toward modifying texts. For example, new technologies make the tracking of readers' eye movements increasingly less obtrusive, as does the recording of galvanic skin response and other physiological factors associated with measuring anxiety. These too might be used to determine when readers are having difficulty and to implement automatically some appropriate adaptations of a text.

Digital texts can also be less difficult than printed texts because they make available a wider range of symbol systems that can provide assistance to individual readers. For example, Olson (Olson \& Wise, 1987), Reitsma (1988), and more recently my colleague Michael McKenna (1998) have studied respectively the effects of providing beginning readers synthesized and digitized pronunciations of unfamiliar words in texts displayed on the computer screen. Although they have been more interested in how such assistance effects decoding and sight-word learning, their work illustrates how digital texts can make texts easier by reducing unknown 
words to only those not in a readers' listening vocabulary. Further, if the word's meaning is unknown, for example, jovial, a computer could also provide a video illustrating a context in which someone exhibited this emotion.

Digital texts might also be less difficult and more engaging because they entail a variety of symbol systems. For example, Pavio (1986) has proposed the "dual encoding" hypothesis to suggest that learning is enhanced when information is encoded through both a linguistic channel and a visual channel as opposed to one or the other.

How can the relative difficulty of texts be established and compared when such assistance is available? Or is textual difficulty and entirely outmoded concept in digital texts? How far above their independent level (i.e., as established with printed texts) may readers choose to read when such assistance is available? Is it more beneficial under some conditions for the computer as opposed to the individual reader to select the amount or type of assistance? Do readers need guidance and practice in making such choices? These and similar questions related to textual difficulty become relevant when engaged reading is considered in relation to digital texts.

\section{Fulfilling a Broad Range of Needs}

Readers will be more engaged when reading fulfills a broad range of psychological and social needs. Theorists and researchers have recognized that reading is an activity that meets specific psychological and social needs that in turn affects the degree to which individuals become engaged in reading. Indeed, the psychological and social dimensions of literacy that affect engagement may be inseparable (see De Temple \& Snow, chap. 3, and Bus, chap. 2, this volume). For example, Nell (1988) analyzed the psychological gratifications associated with readers who seek the pleasurable sensation of being "lost in a book." Other researchers have investigated the relation between television viewing and reading in terms of meeting differing social and psychological needs. Some (e.g., Neuman, 1991) argue that television and reading meet different psychological and social needs and are thus not competitive activities, whereas others see a more competitive relation (see van der Voort, chap. 5 , this volume). Historically, engagement in reading and writing has been affected by sociocultural factors (Kauffer \& Carley, 1993; Olson, 1994). For example, prior to the modern era, reading was much more of a social activity involving oral reading, as opposed to the predominantly silent solitary experience it is today.

Electronic texts, because they entail a wider variety of symbol systems and an expanded range of opportunities for highly participatory social interaction (see Garner \& Gillingham, 1998; Rheingold, 1993), may meet a wider variety of social and psychological needs, both directly and indirectly. An indirect effect may be achieved by creating a more attractive and 
;' listening vocabulary. Further, if the ıple, jovial, a computer could also prohich someone exhibited this emotion. icult and more engaging because they ir example, Pavio (1986) has proposed ggest that learning is enhanced when a linguistic channel and a visual chan-

texts be established and compared $r$ is textual difficulty and entirely outar above their independent level (i.e., ty readers choose to read when such reficial under some conditions for the al reader to select the amount or type dance and practice in making such $s$ related to textual difficulty become nsidered in relation to digital texts.

reading fulfills a broad range of psyits and researchers have recognized ts specific psychological and social o which individuals become engaged and social dimensions of literacy that (see De Temple \& Snow, chap. 3, and e, Nell (1988) analyzed the psychologders who seek the pleasurable sensasearchers have investigated the relareading in terms of meeting differing (e.g., Neuman, 1991) argue that televichological and social needs and are s others see a more competitive relavolume). Historically, engagement in by sociocultural factors (Kauffer \& le, prior to the modern era, reading olving oral reading, as opposed to the ce it is today.

il a wider variety of symbol systems ies for highly participatory social in1998; Rheingold, 1993), may meet a gical needs, both directly and indired by creating a more attractive and functional environment for reading. For example, as I pointed out in the two previous sections, electronic texts are literally interactive, which allows texts to assist more passive and perhaps less skilled readers. Thus, reading might be inherently more appealing to those who are typically inactive during reading. Likewise, removing some of the barriers to decoding and comprehension, which is made possible by electronic texts, may increase the appeal of reading.

Certainly the greater accessibility of electronic texts, at least in theory, plays a role in allowing them to be more appealing. If one has to trek to the library to explore a topic of immediate interest followed by a tedious manual search to find an appropriate source, one is less likely to engage in that activity, especially when success in finding the title of a good book is often followed by the discovery that the book has been checked out. It takes considerable psychological and sometimes physical perseverance to pursue topics of interest under such conditions.

E-mail is an increasingly popular activity that is an example of how electronic texts can more directly meet psychological and social needs. The immediacy of e-mail, which is sometimes exchanged in real time, and its informality make it akin to oral conversations, replacing to some degree the need for activities such as talking on the telephone or composing a formal letter. It can extend offline discussions and interactions, and it encourages collaborative writing and reading through the easy exchange of textual information. The work of Garner and Gillingham $(1996,1998)$ documented the extent to which e-mail and internet connections can meet students' need to consider the narratives of their own lives and the lives of others who may be from entirely different cultural groups and geographical regions. Likewise, electronic texts expand the options for engaging readers in narrative (Murray, 1997), which is central to students' intellectual, social, and personal development (Langer, chap. 9, this volume). For example, Internet activities such as MUDs and MOOs allow students to adopt an imaginary persona in interacting with others in imaginative worlds or adventures. Likewise, students can grow plants remotely over the Internet, and they can interact with astronauts orbiting the earth. In short, electronic texts provide a wide array of need-fulfilling leisure activities not possible in printed materials, and they are thus more likely to increase engagement in reading.

\section{Reading as a Creative and Playful Activity}

Readers will be more engaged when reading is conceived as a less serious and more creative and playful activity. This assertion is to some extent an extension of the previous one stating that electronic texts fulfill a broad range of social and psychological needs. Certainly, engaged reading is promoted through creative and sometimes playful involvement with texts; just 
as certainly, educators have exposed students to such texts in printed form to engage them in reading. However, such an approach may often be viewed as a ploy to capture readers' interest or extend their abilities so that they might become engaged in reading a more serious, culturally valued literature. Electronic texts, on the other hand, in some sense because they allow for easy manipulation of various symbol systems, tend to invite less serious, more creative and playful stances toward reading and writing that are perhaps more naturally engaging.

Several writers have argued that the ascension of electronic media and their less introspective and serious intents have broad cultural implications. For example, Richard Lanham (1993) argued that printed texts are typically more philosophical, while electronic texts are typically more rhetorical. That is, the meaning of printed texts is communicated in a manner that is primarily nonvisual, introspective, and based on the assumption of a contract of "perceptual self denial." As he stated more poetically, "The ideal decorum for prose style [in print] has always been . . . unselfconscious transparency; like the typography that enshrined it, it should be a crystal goblet to set off the wine of thought it contained" (p. 74). In short, printed texts are serious and reflective, encouraging a reader to focus on an author's intent using the essentially nonvisual, and relatively limited, symbol systems available on the printed page.

Some printed texts are purposefully designed to shed this serious intent through whimsical visual presentations (e.g., Wired magazine), but such texts are constrained by the limited symbol systems and modes of presentation available on the printed page. They are noteworthy because they are seeking to transcend the limitations of printed texts. Electronic texts, because they are presented by computers enabling a wide variety of audio and visual effects, represent a medium that more naturally invites readers to look at the textual presentation rather than through it. Meaning in electronic texts is represented less discursively, depending more on nonnotational symbol systems (Salomon, 1979), which in turn encourage personal involvement and interpretation. Moreover, electronic texts strip away the authority and autonomy of the author because they are easily manipulated and modified by the reader. In such an environment, texts project an aura that is simultaneously less serious and less permanent, which also invites a more creative and playful stance.

Lanham (1993) offered a poignant illustration of how such a stance might manifest itself if Milton's Paradise Lost were made available to students on a computer:

Wouldn't [they] begin to play games with it? A weapon in [their] hands after 2,500 years of pompous pedantry about the Great Books. Hey man, how about some music with this stuff? Let's voice this rascal and see what happens. Add 
students to such texts in printed form er, such an approach may often be nterest or extend their abilities so that g a more serious, culturally valued litr hand, in some sense because they alsymbol systems, tend to invite less seices toward reading and writing that

he ascension of electronic media and intents have broad cultural implica(1993) argued that printed texts are ectronic texts are typically more rhe$\mathrm{d}$ texts is communicated in a manner ive, and based on the assumption of a ; he stated more poetically, "The ideal as always been ... unselfconscious tt enshrined it, it should be a crystal t contained" (p. 74). In short, printed uraging a reader to focus on an auvisual, and relatively limited, symbol 2.

y designed to shed this serious intent ins (e.g., Wired magazine), but such ymbol systems and modes of presenhey are noteworthy because they are of printed texts. Electronic texts, beers enabling a wide variety of audio n that more naturally invites readers her than through it. Meaning in elecsively, depending more on nonnota), which in turn encourage personal over, electronic texts strip away the because they are easily manipulated environment, texts project an aura less permanent, which also invites a

ustration of how such a stance might vere made available to students on a

h it? A weapon in [their] hands after he Great Books. Hey man, how about is rascal and see what happens. Add some graphics and graffiti! Print it out in [different fonts] San Francisco for Lucifer and Gothic for God. (p. 7)

This example too points to the cultural implications that may affect the degree to which people become engaged in reading texts. For example, as Purves (1990) argued in his chapter "Becoming a Scribe and Other Unnatural Acts," we live in a "scribal society" in which being literate entails an awareness of literacy that extends far beyond the mechanics of reading and writing. Yet schools tend to treat reading and writing simplistically as if it existed in a cultural vacuum. To promote engaged reading, teachers must portray the richness of literate behaviors. Electronic texts, because they invite playful experimentation, may play a role in heightening teachers' and students' awareness of the cultural complexities of literacy, which is perhaps more engaging. Similarly, electronic texts may change the nature of literacy changing our expectations in a way that makes literacy less intimidating for many teachers and students. Tuman (1992) went so far as to suggest that

[teachers] must confront the possibility that the sustained, detailed crafting of written language is too difficult a task, too removed from normal, informal, sporadic uses of oral language, to be the normative impulse driving a truly democratic language arts curriculum ... [ [ because in doing so] we doom many students to be labeled as failures. (p. 124)

This view is at least indirectly supported by the increasing calls for expanding definitions of literacy to include visual literacy (Flood \& Lapp, 1995) or representational literacy (Cognition and Technology Group at Vanderbilt University, 1994). In short, it may be easier to promote engaged reading and writing when we adopt definitions of literacy that are less serious, and thus less confining. The more informal, sometimes conversational modes of expression that are characteristic of electronic texts, coupled with the availability of easily used tools for blending various symbol systems, may make reading and writing inherently more engaging, more interesting, and less intimidating. Likewise, highly refined skills necessary for a relatively small proportion of students to excel as readers and writers may no longer set them apart and may even put them at some disadvantage because different skills are needed to excel in the creation of electronic texts.

An excellent example of how the less serious, playful aspects of electronic texts could begin to shape an expanded and more enlightened view of literacy among young children is the work of my colleague Linda Labbo (1996). In a 2-year research project she studied how a computer could become an informal literacy tool in a kindergarten classroom. She used the metaphor playland to describe how children in this project used some drawing and writing applications for their imaginary creations on the com- 
puter screen. For children the computer screen became a "playground," a "stage," and a "canvas." Each of these functions reflects a natural form of expression not constrained by the children's relatively limited literacy development but that nonetheless contributes to their development of conventional forms of reading and writing.

\section{AN EXAMPLE OF USING MULTIMEDIA IN CLASSROOMS TO PROMOTE ENGAGED READING}

In this section I provide an overview of a 2-year research project my colleagues and I conducted to investigate if a computer-based activity designed to exploit the multimedia dimensions of electronic texts might effect increases in middle-grade students' independent reading (see Reinking \& Watkins, 1996, for a more detailed description). Specifically, we studied the effects of involving students in creating multimedia reviews of books they read independently. The multimedia book reviews were introduced to teachers and to students as an alternative to the conventional book report. During the 2 years of the project we worked with teachers and students in three schools and in nine classrooms, where we systematically gathered quantitative and qualitative data concerning students' interest in reading inside and outside of school, the amount and type of their reading, teachers' and students' reaction to the activities, unanticipated developments, and so forth. The framework for the investigation was a formative experiment, as described by Newman (1990). In a formative experiment, researchers set a pedagogical goal, introduce an intervention designed to move students toward that goal, determine what factors enhance or inhibit the interventions success in accomplishing the goal, and continually modify the intervention on the basis of knowing those factors. Our pedagogical goal was to increase the amount and diversity of students' independent reading.

\section{Overview of the Intervention and Data Collection}

To enable students to create multimedia book reviews on the computer, we first introduced them and their teachers to Hypercard, a widely used Macintosh application that permits users considerable flexibility in creating interlinked texts that can include prose, graphical displays, and audio. We taught teachers and students the basics of Hypercard, including how to enter texts, how to include graphical displays (created by using the drawing tools or by cutting and pasting clip art) and audio effects into Hypercard documents, and how to create "buttons" that linked the screens or "cards" in a Hypercard program or "stack." During the first year of the project, the researchers and graduate assistants from the university taught students 
uter screen became a "playground," a se functions reflects a natural form of hildren's relatively limited literacy deitributes to their development of conng.

\section{IMEDIA IN NGAGED READING}

$N$ of a 2-year research project my colgate if a computer-based activity deensions of electronic texts might effect independent reading (see Reinking \& scription). Specifically, we studied the ing multimedia reviews of books they ia book reviews were introduced to Iative to the conventional book report. worked with teachers and students in ns, where we systematically gathered ncerning students' interest in reading ount and type of their reading, teachctivities, unanticipated developments, investigation was a formative experi). In a formative experiment, researchan intervention designed to move stuwhat factors enhance or inhibit the ng the goal, and continually modify the $g$ those factors. Our pedagogical goal 'sity of students' independent reading.

\section{Data Collection}

dia book reviews on the computer, we achers to Hypercard, a widely used ers considerable flexibility in creating se, graphical displays, and audio. We ics of Hypercard, including how to ensplays (created by using the drawing art) and audio effects into Hypercard ns" that linked the screens or "cards" uring the first year of the project, the from the university taught students how to use Hypercard and how to create multimedia book reviews, although students' teachers assisted while learning along with the students. During the second year, teachers took charge of teaching students how to use Hypercard and how to create multimedia book reviews. After students became familiar with Hypercard, they collaborated to develop a standard template with specific categories of information related to books they read. A standard template was necessary because the ultimate goal of the project was to construct a searchable database of books students had read, so that other students, teachers, and parents could search the database to find books to read, to see what a particular student was reading, and so forth. Nonetheless, each template contained a button labeled "More About This Book," which was linked to unique cards created by individual students who could add various information as prose, pictures imported from clipart files or drawn using drawing tools, sound effects, and so forth. Although not searchable from the database, this option allowed each student to go beyond the standard template.

Figure 10.1 shows the three linked cards that comprise the book review template that was developed with input from teachers and students. Each student used this template as a starting point for creating their multimedia book reviews. The card shown in Fig. 10.1(a) serves as a menu showing as

(a)

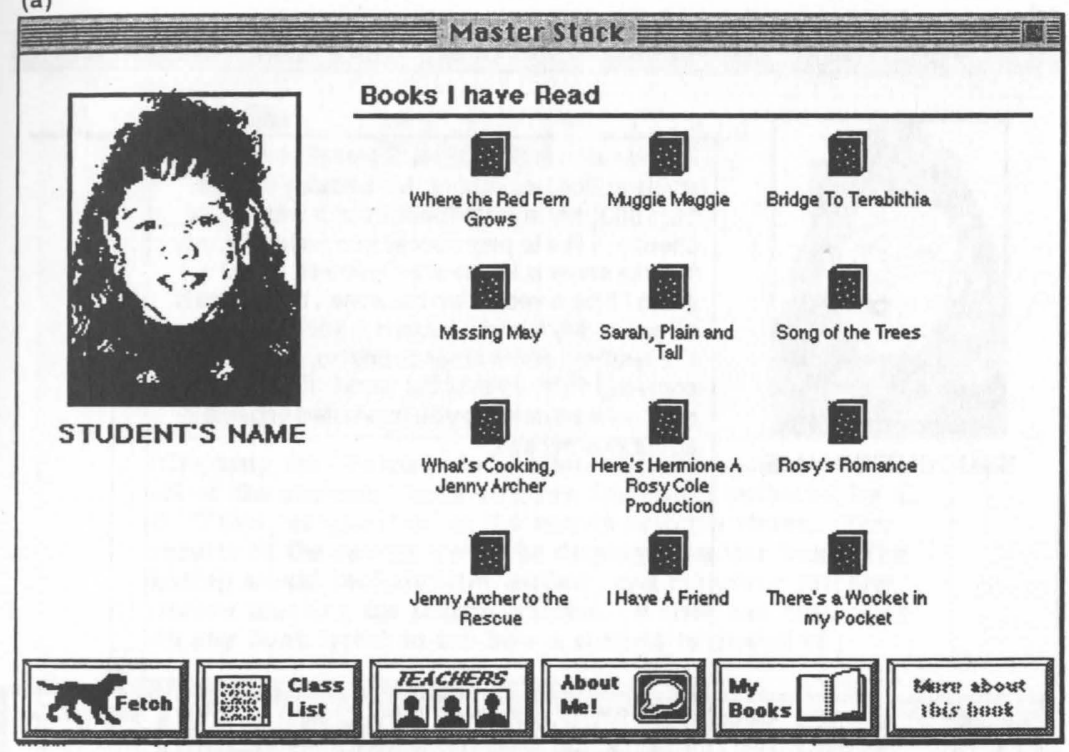

FIG. 10.1a. Three cards that comprised the book review template. (a) Template card 1: Main menu screen showing the books a student has read and reviewed. 


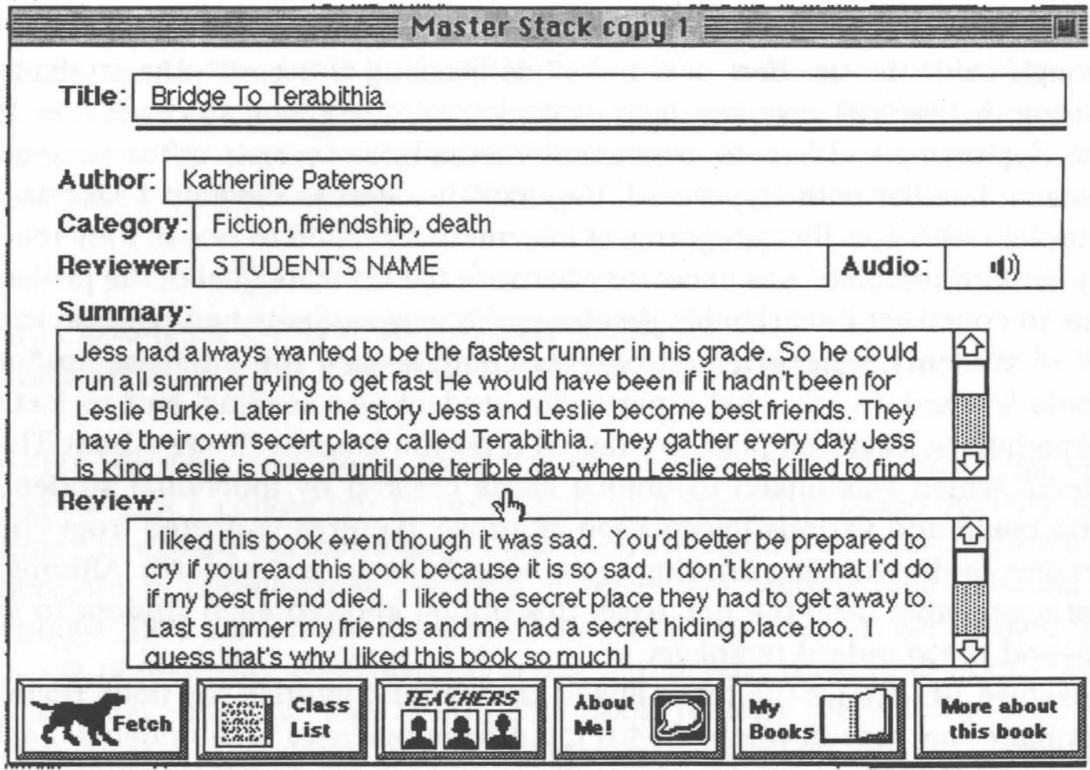

FIG. 10.1b. (b) Template card 2: Review screen completed by students for each book reviewed.

(c)

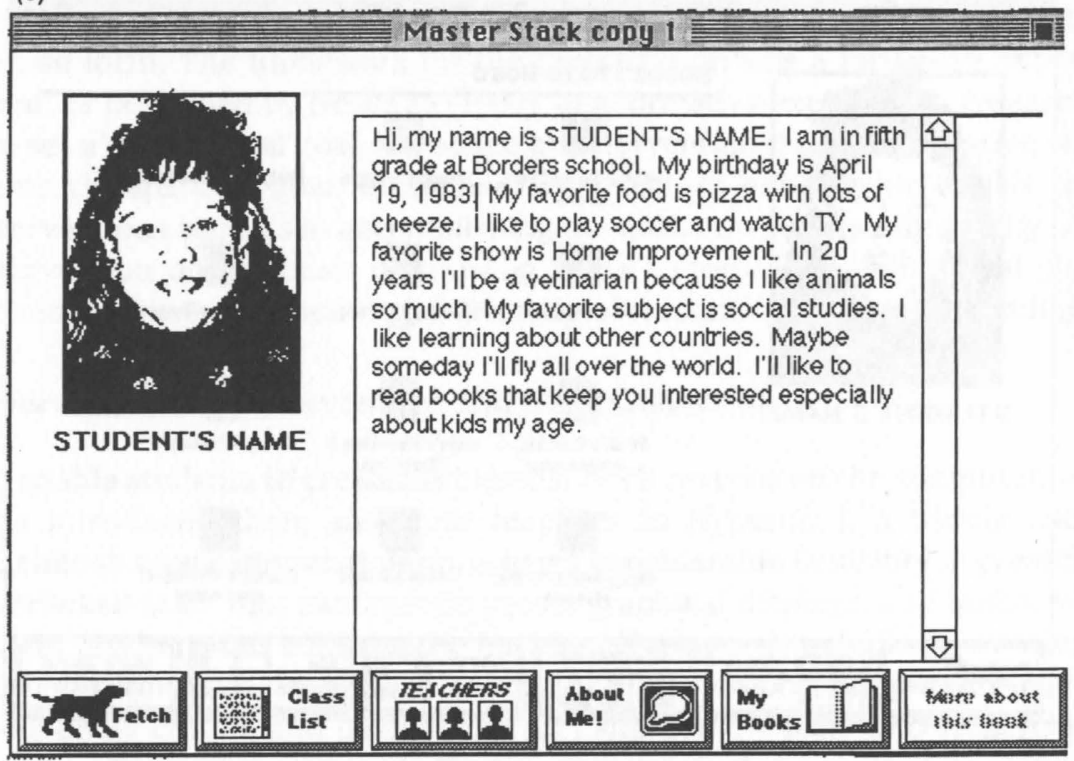

FIG. 10.1c. (c) Template card 3: Student-written biographical sketch. 
icons the books a student has read and reviewed. Clicking on one of the book icons revealed a second card in the template card [Fig. 10.1(b)], where students provided information about the book and their reaction to it. Clicking on the "About Me" button revealed a third card in the template [Fig. 10.1(c)], providing a brief biographical sketch that students wrote about themselves. The card displayed in Fig. 10.2 shows the search screen from which the database of all students' reviews could be searched across the various categories of information in the templates. Anyone exploring the book reviews could also begin by clicking on a picture of a teacher to see a list of the students in that teacher's class and could then select a student to go to the menu template shown in Fig. 10.1(a).

Throughout the project, we collected qualitative data that included semistructured interviews with teachers, students, and parents; observations in the classroom and school, which were recorded as field notes or as tape recordings that were later transcribed; teacher logs in which teachers recorded their observations about the project; and focus-group discussions with teachers and students. Quantitative measures were employed before the intervention was introduced to establish baseline data and again at the end of the school year to determine if there were statistical differences among the experimental classrooms and two comparison classrooms using the Accelerated Reader, a program aimed at increasing students' reading by providing computer-based tests to determine if a student could receive
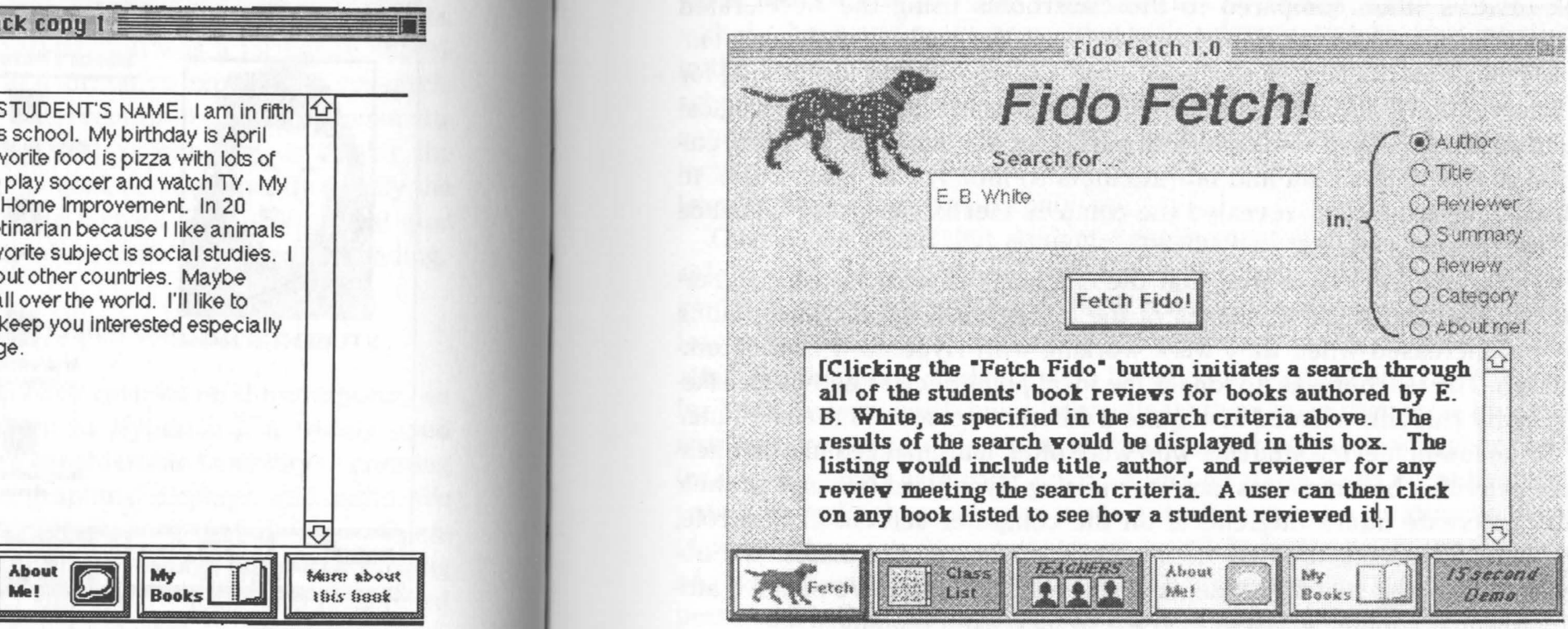

FIG. 10.2. "Fido Fetch" screen used to direct the search of the database containing all students' reviews. 
credit for reading a book. Unlike the multimedia book review project, which was the focus of our study, the Accelerated Reader program is based on extrinsic motivation because students are typically provided with some reward for achieving certain point totals, as was the case in the comparison classrooms in our study. To investigate the effects of the project over the course of a school year, quantitative measures included the Teacher Orientation to Reading Instruction (TORP; see DeFord, 1985) to determine if teachers changed their orientation to teaching reading; the Elementary Reading Attitude Survey (ERAS, see McKenna \& Kear, 1990) to determine if students' attitudes toward reading changed in school and out of school; and two researcher-developed, Lickert-scale surveys, one for students and one for their parents, to determine any changes in students' attitudes, behaviors, and preferences regarding reading in and outside of school.

\section{Summary of Findings}

Both the quantitative and qualitative data indicated that involvement in creating multimedia book reviews increased the amount of students' independent reading across the schools and classrooms, but there was considerable variation in its effectiveness with particular students in particular classrooms. The analysis of the quantitative data revealed statistically significant effects in favor of several classrooms involved in using multimedia book reviews when compared to the classrooms using the Accelerated Reader program. However, more insightful were the qualitative data that informed us about the factors that seemed to be important in accounting for the intervention's success or lack of success in achieving the pedagogical goal in particular classrooms and with particular students. The ongoing collection of qualitative data and our attempts to modify the intervention to address relevant factors revealed the complex mechanisms that influence the intervention's effects.

For example, we discovered that the challenge of working with Hypercard changed the social dynamics of the classrooms. Interactions among students increased when they were working with Hypercard in the computer lab. The teacher was no longer the focal point of class activities. Likewise, many students seemed to acquire a different persona in the computer lab. Some low-achieving students who were often marginalized in other academic activities became class experts in using Hypercard because of their ability to create interesting effects on the computer screen. In that role, they were often consulted by their higher achieving classmates. We observed some low-achieving students in this role develop more positive attitudes toward reading, which in turn led to increased reading.

However, our formative approach also revealed that under some circumstances the compilation of the book reviews into a database discouraged 
multimedia book review project, which erated Reader program is based on exare typically provided with some re ls, as was the case in the comparison iate the effects of the project over the measures included the Teacher OrienP; see DeFord, 1985) to determine if to teaching reading; the Elementary McKenna \& Kear, 1990) to determine if shanged in school and out of school; rrt-scale surveys, one for students and ıny changes in students' attitudes, beeading in and outside of school.

data indicated that involvement in creeased the amount of students' indeand classrooms, but there was considwith particular students in particular ititative data revealed statistically sigssrooms involved in using multimedia le classrooms using the Accelerated shtful were the qualitative data that inned to be important in accounting for success in achieving the pedagogical particular students. The ongoing coltempts to modify the intervention to complex mechanisms that influence

the challenge of working with Hyperthe classrooms. Interactions among working with Hypercard in the comthe focal point of class activities. Likee a different persona in the computer were often marginalized in other acain using Hypercard because of their n the computer screen. In that role, nigher achieving classmates. We obthis role develop more positive attied to increased reading.

lso revealed that under some circumreviews into a database discouraged low-achieving students from participating in the activity. For example, in one classroom with a relatively high percentage of students reading below grade level, the low-achieving students resisted creating book reviews, even though working on the computer seemed to be enjoyable to them. In analyzing this situation, we discovered that low-achieving students did not want to enter books into the database because they could only enter books below grade level, which made their limited reading ability public. We discussed this situation with the classroom teacher, who proposed a simple and effective solution. She announced the next day that because the database would be used by children in lower grades, that she hoped some of the class would review easier books for younger children who would be using the database to find books to read. This strategy worked. Shortly thereafter we found that one low-achieving reader in the class began to enter many book reviews. Because this student was seen as a leader among the low-achieving students, his involvement seemed to sanction the activity for other students, who quickly followed suit.

The challenge of using Hypercard to create multimedia book reviews also subtly mediated increases in the amount and diversity of students' independent reading. That is, students became aware of various books in the process of learning about Hypercard or in helping each other create reviews. For example, in working with a small group of students to explain how audio could be included in a Hypercard program, I asked a student to get a book he was currently reading to use an example. When he returned with the book and as we proceeded with a demonstration, another student in the group asked him if it was a good book. In a subsequent visit to the school a few days later, I saw the book on the second student's desk. She responded affirmatively when I asked her if she was reading it. Thus, her selection of this book seemed to be directly mediated by her involvement in learning how to use the technology.

Overall, we found that students' engagement with literacy activities inside and outside the school increased while they participated in using the computer to create multimedia book reviews. We also saw evidence that at least some of the assertions discussed previously in this chapter were operating. For example, students were involved in creating and later searching for book reviews much more interactively than when they were involved in writing a conventional book report that was submitted to a teacher and typically not shared with their peers. Although there were no purposeful attempts to make the reading of the text itself easier, the multimedia book review activity created an environment in which students across a wide range of achievement levels could succeed. That success and the more social aspects of creating multimedia book reviews suggest that this activity met a broader range of psychological and social needs than would reading a book and submitting a written book review. Likewise, the atmosphere during the 
multimedia book review activity was decidedly less formal and more playful than in other academic activities during the school day. Teachers generally were more tolerant of unstructured time and interactions among students. The content of the multimedia book reviews themselves was more whimsical and humorous. One memorable example was when students used their Hypercard skills to create a special Valentine's Day stack for their teacher. The valentine presented a story that contained some goodnatured teasing of the unmarried teacher's boyfriend. Thus, among the findings of this research project, it is possible to see evidence of how the multimedia dimension of electronic texts might promote engaged reading.

\section{CONCLUSIONS AND DISCUSSION}

The tack that might be taken in examining the topic of multimedia and engaged reading is likely to vary depending on one's conception of and investment in literacy. For some, literacy emanates exclusively from print. They are heavily invested in books-culturally, educationally, and for some, professionally or materially. To them, electronic reading and writing, which make multimedia an issue, are interlopers in an almost sacred domain. A lifetime of positive experiences associated with reading books for pleasure and edification powerfully sustains this orientation to some degree in virtually every adult today who might be described as an engaged reader.

However, to those who unabashedly and unapologetically believe that the digital world is a threat to the longstanding and inherently superior typographic one, my conclusions will be unpalatable. For in this chapter I have argued that multimedia-more technically speaking, the multiple symbol systems available to the new medium of electronic texts-creates a reading experience that is inherently more engaging than printed materials. Electronic texts that exploit multimedia inherently foster engagement because they naturally promote an active orientation to reading, are easier to read for more readers, fulfill a broad range of social and psychological needs, and more naturally make reading a creative, playful, and less serious activity.

Underlying my argument is a theoretical framework suggesting that electronic texts, identified in no small measure by their capabilities to subsume many symbol systems, represent an entirely new medium for reading and writing. Using Salomon's (1979) theory of media, I have argued that the multimedia capabilities of electronic texts are more expansive than printed texts in each of the four areas defining any medium: symbol systems, technologies, contents, and contexts.

Thus, electronic texts, I would argue, should be seen as no less divergent from printed texts than printed texts were from the handwritten documents 
decidedly less formal and more playuring the school day. Teachers genered time and interactions among stubook reviews themselves was more orable example was when students : a special Valentine's Day stack for d a story that contained some goodrer's boyfriend. Thus, among the findible to see evidence of how the multinight promote engaged reading.

\section{$\mathbf{N}$}

ining the topic of multimedia and enng on one's conception of and investnanates exclusively from print. They lly, educationally, and for some, proectronic reading and writing, which pers in an almost sacred domain. A ated with reading books for pleasure s orientation to some degree in virtulescribed as an engaged reader.

ly and unapologetically believe that sstanding and inherently superior tye unpalatable. For in this chapter I chnically speaking, the multiple symedium of electronic texts-creates a lore engaging than printed materials. lia inherently foster engagement beorientation to reading, are easier to range of social and psychological g a creative, playful, and less serious

tical framework suggesting that elecsure by their capabilities to subsume ntirely new medium for reading and of media, I have argued that the muls are more expansive than printed any medium: symbol systems, tech-

, should be seen as no less divergent ere from the handwritten documents that preceded them. Just as the printing press had profound effects on engagement in reading in an earlier era, electronic texts represent a similar promise today. However, it is unlikely that we will begin to capitalize on the potential of electronic texts to promote engagement in reading until we accept electronic texts on their own unique terms, without seeing them as some variation, if not aberration, of print, particularly books. We might do well to guard against the shortsightedness that led an official in the 16th century to argue for the status quo by asking the following rhetorical questions about the new printed book:

Could a portable, private instrument like the new book take the place of a book made by hand and memorized as one made it? Could a book which could be read quickly and even silently take the place of a book read slowly aloud? Could students trained by such printed books measure up to the skilled orators and disputants produced by manuscript means?

Taking a similar view toward multimedia and engaged reading in an increasingly digital world may be more than shortsighted or riskier than simply looking foolish to future generations. It may actually undermine the goals even the most ardent bibliophile wishes to promote. That is, there are many reasons to believe that the engaging aspects of electronic texts are already enhancing the goals of conventional literacy based on print. For example, electronic forms of reading and writing have been shown to support the emergent literacy of beginning readers in ways that allow them to move naturally between electronic and printed forms of expression (Labbo, 1996). Multimedia encyclopedias pique interest in topics that are often pursued in conventional printed books. One of the most popular commercial Web sites is for a company that allows users to search for and order books. These examples suggest that more research is needed to explore not only how electronic texts can exploit multimedia to promote engaged reading but also how electronic and printed texts can be mutually supportive in achieving the over arching goal of engaged reading.

Avoiding the potential of digital texts to promote engaged reading also risks the possibility that we will inadequately prepare our children for the future digital world. Today, educators are faced with the formidable challenge of helping children become literate for a digital world that cannot be clearly seen from our current vantage point. Perhaps even more difficult for today's educators is to inculcate in children a literacy that they themselves have not fully acquired. In any event, it is inconceivable that engaged reading in the future will not entail electronic texts. A significant part of addressing that reality is inevitably to think seriously about the role of multimedia in promoting engaged reading in an increasingly digital world. 


\section{REFERENCES}

Alvermann, D. E., \& Guthrie, J. (1993). The national reading research center. In A. Sweet \& J. I. Anderson (Eds.), Reading Research in the year 2000 (pp. 129-150). Hillsdale, NJ: Lawrence Erlbaum Associates.

Baker, L., Afflerbach, P., \& Reinking, D. (Eds.). (1996). Developing engaged readers in school and home communities. Mahwah, NJ: Lawrence Erlbaum Associates.

Barthes, R. (1974). S/Z(R. Miller, Trans). New York: Hill \& Wang. (Original work published 1970)

Birkerts, S. (1994). The Gutenberg elegies: The fate of reading in an electronic age. Boston: Faber \& Faber.

Blohm, P. J. (1982). Computer-aided glossing and facilitated learning in prose recall. In J. A. Niles \& L. A. Harris (Eds.), New inquiries in reading research and instruction (pp. 24-28). Thirty-First Yearbook of the National Reading Conference. Rochester, NY: National Reading Conference.

Blohm, P. J. (1987). Effect on [sic] lookup aids on mature readers' recall of technical text. Reading Research and Instruction, 26, 77-88.

Bolter, J. D. (1991). Writing space: The computer, hypertext, and the history of writing. Hillsdale, NJ: Lawrence Erlbaum Associates. [Also available as hypertext computer program]

Cognition and Technology Group at Vanderbilt University. (1994). Multimedia environments for developing literacy in at-risk students. In B. Means (Ed.), Technology and education reform: The reality behind the promise (pp. 23-56). San Francisco, CA: Jossey-Bass.

Collier, R. M. (1983). The word processor and revision strategies. College Composition and Communication, 34, 149-155.

Daiute, C. (1986). Physical and cognitive factors in revising: Insights from studies with computers. Research in the Teaching of English, 20, 141-159.

DeFord, D. E. (1985). Validating the construct of theoretical orientation in reading instruction. Reading Research Quarterly, 20, 351-367.

Fish, M. C., \& Feldman, S. C. (1987). A comparison of reading comprehension using print and microcomputer presentation. Journal of Computer-Based Instruction, 14, 57-61.

Flood, J., \& Lapp, D. (1995). Broadening the lens: Toward an expanded conceptualization of literacy. In K. A. Hinchman, D. J. Leu, \& C. K. Kinzer (Eds.), Perspectives on literacy research and practice: The 44th Yearbook of the National Reading Conference (pp. 1-16). Chicago: National Reading Conference.

Gambrell, L. B., Bradley, V. N., \& McLaughlin, E. M. (1987). Young children's comprehension and recall of computer screen displayed text. Journal of Research in Reading, 10, 156-163.

Garner, R., \& Gillingham, M. G. (1996). Conversations across time, space, and culture: Internet communication in six classroom. Hillsdale, NJ: Lawrence Erlbaum Associates.

Garner, R., \& Gillingham, M. G. (1998). The internet in the classroom: Is it the end of transmissionoriented pedagogy? In D. Reinking, M. C. McKenna, L. D. Labbo, \& R. Kieffer (Eds.), Handbook of literacy and technology: Technological transformations in a post-typographic world (pp. 221-233) Mahwah, NJ: Lawrence Erlbaum Associates.

Gould, J. D., \& Gischkowsky, N. (1983). Doing the same work with paper and cathode ray tube displays (CRT). Human Factors, 24, 329-338.

Hansen, W. J., Doring, R. R., \& Whitlock, L. R. (1978). Why an examination was slower on-line than on paper. International Journal of Man-Machine Studies, 10, 507-519.

Hegarty, M., Carpenter, P. A., \& Just, M. A. (1991). Diagrams in the comprehension of scientific texts. In R. Barr, M. L. Kamil, P. Mosenthal, \& P. D. Pearson (Eds.), Handbook of reading research (Vol. 2, pp. 641-668). New York: Longman.

Heppner, F. H., Anderson, J. G. T., Farstrup, A. E., \& Weidermann, N. H. (1985). Reading performance on a standardized test is better from print than from computer display. Journal of Reading, 28, 321-325. 
nal reading research center. In A. Sweet \& J. I. Anear 2000 (pp. 129-150). Hillsdale, NJ: Lawrence

1996). Developing engaged readers in school and Erlbaum Associates.

ork: Hill \& Wang. (Original work published 1970) te of reading in an electronic age. Boston: Faber \&

d facilitated learning in prose recall. In J. A. Niles g research and instruction (pp. 24-28). Thirty-First ce. Rochester, NY: National Reading Conference. mature readers' recall of technical text. Reading

hypertext, and the history of writing. Hillsdale, $\mathrm{NJ}$ : ble as hypertext computer program]

University. (1994). Multimedia environments for Means (Ed.), Technology and education reform: an Francisco, CA: Jossey-Bass.

evision strategies. College Composition and Com-

in revising: Insights from studies with comput141-159.

theoretical orientation in reading instruction.

of reading comprehension using print and miiter-Based Instruction, 14, 57-61.

Toward an expanded conceptualization of literzer (Eds.), Perspectives on literacy research and ading Conference (pp. 1-16). Chicago: National

1. (1987). Young children's comprehension and urnal of Research in Reading, 10, 156-163.

ns across time, space, and culture: Internet comvrence Erlbaum Associates.

in the classroom: Is it the end of transmissionenna, L. D. Labbo, \& R. Kieffer (Eds.), Handbook nsformations in a post-typographic world (pp. sociates.

ame work with paper and cathode ray tube dis-

. Why an examination was slower on-line than e Studies, 10, 507-519.

Diagrams in the comprehension of scientific P. D. Pearson (Eds.), Handbook of reading rehan.

Weidermann, N. H. (1985). Reading performthan from computer display. Journal of Read-
Kaufer, D. S., \& Carley, K. M. (1993). Communication at a distance: The influence of print on sociocultural organization and change. Hillsdale, NJ: Lawrence Erlbaum Associates.

Kruk, R. S., \& Muter, P. (1984). Reading continuous text on video screens. Human Factors, 26 , 339-345.

L'Allier, J. J. (1980). An evaluation study of a computer-based lesson that adjusts reading level by monitoring on task reader characteristics. Unpublished doctoral dissertation, University of Minnesota, Minneapolis, MN.

Labbo, L. D. (1996). A semiotic analysis of young children's symbol making in a classroom computer center. Reading Research Quarterly, 31(4), 356-385.

Landow, G. (1992). Hypertext: The convergence of contemporary critical theory and technology. Baltimore, MD: Johns Hopkins University Press.

Lanham, R. A. (1993). The electronic word: Democracy, technology, and the arts. Chicago: University of Chicago Press.

Larson, D. (1993). Marble Springs [Computer software]. Cambridge, MA: Eastgate Systems.

Leu, D. J., \& Reinking, D. (1996). Bringing insights from reading research to research on electronic learning environments. In H. V. Oostendorp \& S. D. Mul (Eds.), Cognitive aspects of electronic text processing (pp. 43-75). Norwood, NJ: Ablex.

MacGregor, S. K. (1988a). Instructional design for computer-mediated text systems: Effects of motivation, learner control, and collaboration on reading performance. Journal of Experimental Education, 56, 142-147.

MacGregor, S. K. (1988b). Use of self-questioning with a computer-mediated text system and measures of reading performance. Journal of Reading Behavior, 20, 131-148.

McKenna, M. C. (1998). Electronic texts and the transformation of beginning reading. In D. Reinking, M. C. McKenna, L. D. Labbo, \& R. Kieffer (Eds.), Handbook of literacy and technology: Technological transformations in a post-typographic world (pp. 45-59) Mahwah, NJ: Lawrence Erlbaum Associates.

McKenna, M. C., \& Kear, D. J. (1990). Measuring attitude toward reading: A new tool for teachers. Reading Teacher, 43, 626-639.

Murray, J. H. (1997). Hamlet on the holodeck: The future of narrative in cyberspace. New York: Free Press.

Muter, P., Latremouille, S., Treurniet, W., \& Beam, P. (1982). Extended reading of continuous text on television screens. Human Factors, 24, 501-508.

Nell, V. (1988). The psychology of reading for pleasure: Needs and gratifications. Reading Research Quarterly, 23, 6-50.

Neuman, S. B. (1991). Literacy in the television age: The myth of the TV effect. Norwood, NJ: Ablex.

Newman, D. (1990). Opportunities for research on the organizational impact of school computers. Educational Researcher, 19, 8-13.

Olson, D. R. (1994). The world on paper: The conceptual and cognitive implications of writing and reading. New York: Cambridge Press.

Olson, R. K., \& Wise, B. W. (1987). Computer speech in reading instruction. In D. Reinking (Ed.), Reading and computers: Issues for theory and practice (pp. 156-177). New York: Teachers College Press.

Ong, W. (1982). Orality and literacy: The technologizing of the word. New York: Methuen.

Pavio, A. (1986). Mental representation: A dual encoding approach. New York: Oxford University Press.

Purves, A. C. (1990). The scribal society. New York: Longman.

Reinking, D. (1988). Computer-mediated text and comprehension differences: The role of reading time, reader preference, and estimation of learning. Reading Research Quarterly, 23, 484-498.

Reinking, D. (1992). Differences between electronic and printed texts: An agenda for research. Journal of Educational Multimedia and Hypermedia, 1(1), 11-24. 
Reinking, D. (1994). Electronic literacy (Perspective in Reading Research No. 4). Athens, GA: National Reading Research Center, University of Georgia, University of Maryland.

Reinking, D. (1995). Reading and writing with computers: Literacy research in a post-typographic world. In K. A. Hinchman, D. J. Leu, \& C. K. Kinzer (Eds.), Perspectives on literacy research and practice: The 44th Yearbook of the National Reading Conference (pp. 17-33).

Reinking, D. (1997). Me and my hypertext:) A multiple digression analysis of technology and literacy. Reading Teacher, 50, 626-643.

Reinking, D. (1998). Synthesizing technological transformations of literacy in a post-typographic world. In D. Reinking, M. C. McKenna, L. D. Labbo, \& R. Kieffer (Eds.), Handbook of literacy and technology: Technological transformations in a post-typographic world (pp. xi-xxx). Mahwah, NJ: Lawrence Erlbaum Associates.

Reinking, D., \& Bridwell-Bowles, L. (1991). Computers in reading and writing research. In P. D. Pearson (Ed.), Handbook of reading research (Vol. II, pp. 310-340). New York: Longman.

Reinking, D., McKenna, M. C., Labbo, L. D., \& Kieffer, R. D. (Eds). (1998). Handbook of literacy and technology: Transformations in a post-typographic world. Mahwah, NJ: Lawrence Erlbaum Associates.

Reinking, D., Pickle, M. \& Tao, L. (1996). The effects of inserted questions and mandatory review in computer-mediated texts (Reading Research Report \#50). Athens, GA: National Reading Research Center.

Reinking, D., \& Rickman, S. S. (1990). The effects of computer-mediated texts on the vocabulary learning and comprehension of intermediate-grade readers. Journal of Reading Behavior, 22, 395-411.

Reinking, D., \& Schreiner, R. (1985). The effects of computer-mediated text on measures of reading comprehension and reading behavior. Reading Research Quarterly, 20, 536-552.

Reinking, D., \& Watkins, J. (1966). A formative experiment investigating the use of multimedia book reviews to increase elementary students' independent reading. Reading Research Quarterly, 35, 384-419.

Reitsma, P. (1988). Reading practice for beginners: Effects of guided reading, reading-whilelistening, and independent reading with computer-based speech feedback. Reading Research Quarterly, 23, 219-235.

Rheingold, H. (1993). The virtual community: Homesteading on the electronic frontier. Reading, MA: Addison-Wesley.

Salomon, G. (1979). Interaction of media, cognition, and learning. San Francisco: Jossey-Bass.

Salomon, G., Globerson, T., \& Guterman, E. (1989). The computer as a zone of proximal development: Internalizing reading-related metacognitions from a reading partner. Journal of Educational Psychology, 81, 620-627.

Salomon, G., Perkins, D. N., \& Globerson, T. (1991). Partners in cognition: Extending human intelligence with intelligent technologies. Eductional Researcher, 20(3), 2-9.

Sherwood, R. D., Kinzer, C. K., Hasselbring, S., \& Bransford, J. D. (1987). Macro-contexts for learning: Initial findings and issues. Applied Cognitive Psychology, 1, 93-108.

Spiro, R. J., Coulson, R. L., Feltovich, P. J., \& Anderson, D. K. (1988). Cognitive flexibility theory: Advanced knowledge acquisition in ill-structured domains (Tech. Rep. No. 441). UrbanaChampaign: University of Illinois, Center for the Study of Reading.

Spiro, R. J., Feltovich, P. J., Jacobson, M. J., \& Coulson, R. L. (1992). Cognitive flexibility, constructivism, and hypertext: Random access instruction for advanced knowledge acquisition in ill-structured domains. In T. M. Duffy \& D. H. Jonassen (Eds.), Constructivism and the technology of instruction: A conversation (pp. 57-75). Hillsdale, NJ: Lawrence Erlbaum Associates.

Stahl, S. A, Hynd, C. R., Britton, B. K., McNish, M. M., \& Bosquet, D. (1996). What happens when students read multiple source documents in history? Reading Research Quarterly, 4, 430-456.

Stanovich, K. E. (1986). Matthew effects in reading: Some consequences of individual differences in the acquisition of literacy. Reading Research Quarterly, 21, 360-407. 
ve in Reading Research No. 4). Athens, GA: Naof Georgia, University of Maryland. computers: Literacy research in a post-typo\& C. K. Kinzer (Eds.), Perspectives on literacy ree National Reading Conference (pp. 17-33). iltiple digression analysis of technology and lit-

ansformations of literacy in a post-typographic bbo, \& R. Kieffer (Eds.), Handbook of literacy and a post-typographic world (pp. xi-xxx). Mahwah,

outers in reading and writing research. In P. D. (Vol. II, pp. 310-340). New York: Longman. ffer, R. D. (Eds). (1998). Handbook of literacy and hic world. Mahwah, NJ: Lawrence Erlbaum Asso-

ts of inserted questions and mandatory review in Report \#50). Athens, GA: National Reading Re-

of computer-mediated texts on the vocabulary -grade readers. Journal of Reading Behavior, 22 ,

f computer-mediated text on measures of read'eading Research Quarterly, 20, 536-552.

periment investigating the use of multimedia book indent reading. Reading Research Quarterly, 35,

1ers: Effects of guided reading, reading-whileuter-based speech feedback. Reading Research

esteading on the electronic frontier. Reading, MA:

$n$, and learning. San Francisco: Jossey-Bass.

. The computer as a zone of proximal developitions from a reading partner. Journal of Educa-

. Partners in cognition: Extending human intelnal Researcher, 20(3), 2-9.

ransford, J. D. (1987). Macro-contexts for learntive Psychology, 1, 93-108.

rson, D. K. (1988). Cognitive flexibility theory: Adred domains (Tech. Rep. No. 441). Urbanathe Study of Reading.

\& Coulson, R. L. (1992). Cognitive flexibility, s instruction for advanced knowledge acquisi\& D. H. Jonassen (Eds.), Constructivism and the 7-75). Hillsdale, NJ: Lawrence Erlbaum Associ-

M., \& Bosquet, D. (1996). What happens when istory? Reading Research Quarterly, 4, 430-456.

: Some consequences of individual differences ch Quarterly, 21, 360-407.
Tobias, S. (1987). Mandatory text review and interaction with student characteristics. Journal of Educational Psychology, 79, 154-161.

Tobias, S. (1988). Teaching strategic text review by computer and interaction with student characteristics. Computers in Human Behavior, 4, 299-310.

Tuman, M. C. (Ed.). (1992). Literacy online: The promise (and peril) of reading and writing with computers. Pittsburgh, PA: University of Pittsburgh Press.

Wright, P. (1987). Reading and writing for electronic journals. In B. K. Britton \& S. M. Glynn (Eds.), Executive control processes in reading (pp. 23-55). Hillsdale, NJ: Lawrence Erlbaum Associates. 